
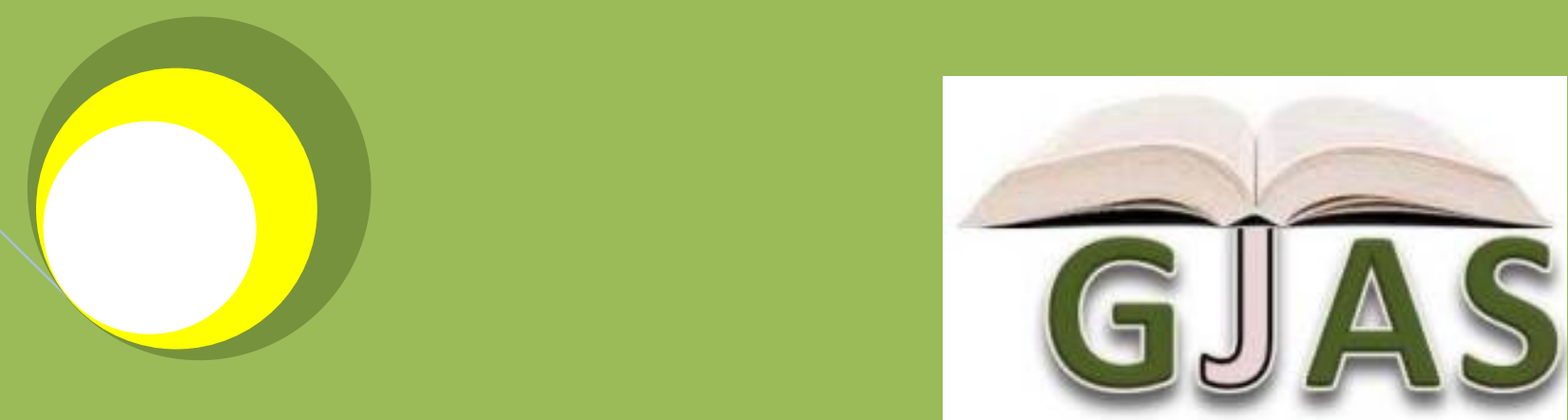

Greener Journal of Agricultural Sciencees

ISSN: 2276-7770 Impact Factor 2012 (UJRI): 0.7904 ICV 2012: 6.15

Insecticide Use in

Cabbage Pest

Management in

Tamale Metropolis of

Ghana

By

Badii K.B.

Adarkwah C.

Nboyine J.A. 


\title{
Insecticide Use in Cabbage Pest Management in Tamale Metropolis of Ghana
}

\author{
Badii K.B. ${ }^{{ }^{\star}}$, Adarkwah C. ${ }^{1}$ and Nboyine J.A. ${ }^{2}$
}

\author{
${ }^{1}$ Department of Agronomy, University for Development Studies, P. O. Box TL 1882, Tamale, N/R, Ghana. \\ ${ }^{2}$ CSIR-Savanna Agricultural Research Institute, P. O. Box TL 52, Tamale, N/R, Ghana. \\ *Corresponding Author's Email: benbadii@yahoo.com
}

\begin{abstract}
The intensive use of agro-insecticides by farmers in the Tamale Metropolis of Ghana has resulted in the detection of high insecticide residues in vegetables, local health hazards and environmental pollution. This study investigated the knowledge and practices of cabbage growers regarding the use of insecticides in the management of insect pests of cabbage. A survey of 70 cabbage farmers was conducted in seven different production sites in the Metropolis. Cabbage farming system in the Metropolis typically consisted of smallholder farmers growing one or two cabbage varieties. The diamondback moth, Plutella xylostella remained the major insect pest in cabbage. More than $90 \%$ of farmers applied pesticides for pest control. There were 12 major types of insecticides used in pest control and each farmer usually used 3-4 types of insecticide over a season. Both high and low toxicity pesticides, with EIQ values ranging between $\mathbf{1 0 . 0}$ and 52.5, were used. Pesticide spray frequency was higher during wet seasons than in the dry seasons. The study also revealed that hypermarkets play an important role in marketing of fresh cabbage in the food chain. Regulations on pesticide residue monitoring need to be applied in order to help address the high insecticide residues on fresh products and their impact on animal and human health in the Metropolis.
\end{abstract}

Keywords: Insecticides, Cabbage, Pest Management, Tamale Metropolis, Ghana.

\section{INTRODUCTION}

Cabbage (Brassica oleracea var capitata) is one of the major vegetables consumed in the Tamale Metropolis of Ghana. It is grown mainly for home consumption and domestic market and it also serves as a source of income for small scale farmers in the metropolis. It is an excellent source of calcium, folic acid, vitamin $\mathrm{C}$ and potassium (Weaver, 1990). During the dry season, its production and sales are major source of income and livelihood for many farm households. Consequently, many farmers in the metropolis embark on production of cabbage on smallholder levels at concentrated areas. Over the years, farmers in the Metropolis have cultivated cabbage more intensively to meet the increasing demand. The intensified production of cabbage has led to a common problem of high pest infestation, with one of the most important insect pest being the diamondback moth, Plutella xylostella (Ooi, 1986). It is the greatest threat to crucifer production in many part of the world, sometimes causing more than $90 \%$ crop loss (lqbal et al., 1996).

Pesticides have been the primary means of controlling P. xylostella and other pests of cabbage for many years (Syed, 1992). There are increasing concerns about the long-term environmental impact of vegetable production in the metropolis, focusing particularly on the heavy use of insecticides with local health hazards, pesticides residues for consumers, the build-up of resistance and contamination of the environment. These problems have increased the interest in alternative control methods, such as crop rotation, biological control and Integrated Pest Management (IPM) (Ooi and Lim, 1983). New technologies, such as the use of transgenic crops and pheromone traps, are starting to overcome the problem of resistance. However, many transgenic crops are derived from Bt Cry-toxin and the use of transgenic crops may be short-lived if pests evolve resistance to Bt Crytoxin due to high selection pressure (Tabashnik, 1994). Moreover, prescribed pheromones for cabbage pest control, apart from their high costs to small scale farmers, generally unavailable in local markets. Another major issue related to the high use of pesticides is residues on fresh produce and vegetables entering the food chain. Due to over-reliance on pesticide application to control pests and to achieve a high-quality appearance of produce, high pesticide residues have been detected on vegetables (Mazlan and Mumford, 2004).

As a result of the continued problems of pest attack coupled with widespread dependence on pesticides, pest resistance and pesticide residues, a study of current knowledge and practices was carried out in the Tamale Metropolis of Ghana in 2012. The major objectives of the study were to obtain baseline information on cabbage pest management practices, particularly the use of insecticides against $P$. xylostella. This information would be useful for evaluating the potential returns of different strategies to reduce the use of pesticides and to decrease 
the incidence of pesticide residues on vegetable crops. It is also essential for an analysis of appropriate points within the food chain at which to monitor and control the flow of residues to consumers.

\section{RESEARCH METHODOLOGY}

\section{Study Area}

Tamale Metropolis is located in the North-central part of Ghana (Lat. $9^{\circ} 16^{\prime}$ and $9^{\circ} 34^{\prime} \mathrm{N}$ and Long. $0^{\circ} 36^{\prime}$ and $0^{\circ}$ 57 ' West, $183 \mathrm{~m}$ asl). It covers a land area of about $750 \mathrm{~km}^{2}$ which is about $13 \%$ of the total land area of the Northern Region of the country. It is known to be the most important vegetable growing district in the region. The terrain is slightly mountainous and dissected with $10-20^{\circ}$ slopes. Soils in the area are derived from Voltaian sandstone with sandy to sandy-loam textures. Mean day and night temperatures range from $33-39^{\circ} \mathrm{C}$ and $20-$ $22^{\circ} \mathrm{C}$, respectively. The area has a mean annual rainfall distribution of $1100 \mathrm{~mm}$ with 95 days intensive rain. The rainfall pattern is uni-modal stretching from April to October, with its peak in July and August (SARI, 2008).

\section{Survey Methods}

The study was a questionnaire survey involving cabbage farmers from 7 production sites in the Tamale Metropolis of Ghana (Figure 1). The selected sites included Bilpiela, Sangani, Choggu, Gumbihini, Gurugu, Kamina and Vitting. These production sites were selected on the basis of farm size, location and proximity. The simple random sampling technique was used so that each cabbage production site represented a stratum (sampling unit). In each site, 10 cabbage growers were selected to answer questionnaire, thus, giving a total of 70 respondents. The methods and tools for data collection were based on procedures for analysing agricultural problems and assessing farmers' Knowledge, Perceptions and Practices (KPP) as documented by Werner (1993). Semi-structured questionnaire, designed in a close- and open-ended fashion were used to assess farmers' KPP about their insecticide use in the management of cabbage pests. Farmers were asked background information; age, production experience, farm size, educational background and cabbage varieties cultivated. They were then questioned on their pest control practices, types of insecticides used in pest control, frequency of chemical spraying during the growing seasons, cabbage production cost and market chain.
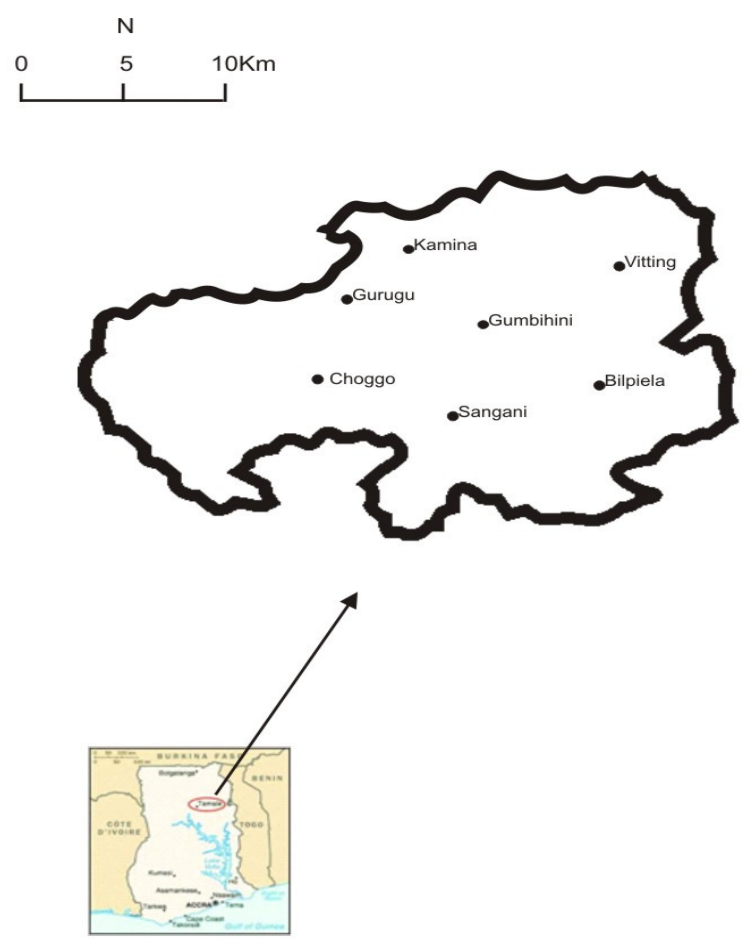

Figure 1: Map of Tamale Metropolis of Ghana showing cabbge producing sites

Content and face validity were established by a panel of experts consisting of researchers from the Department of Agricultural Extension Education of the University for Development Studies (UDS), and a group of 
professionals in entomology at the Savanna Agricultural Research Institute, Ghana. A pilot test was conducted with 10 cabbage growers, not included in the sample, three weeks before the study. After the pilot test, minor changes were made in the expression of some questions. Data were collected using face-to-face interview combined with field observations between February and April, 2012. Interviews were conducted in English or appropriate local languages (for farmers who were illiterates). Each interview lasted on average, 30 minutes. Data were analyzed using appropriate statistical procedures for description (frequencies, percentages, means and standard deviations). Statistical analysis was performed using the Statistical Package for Social Sciences (SPSS for Windows version 16.0).

\section{Classification of the Environmental Impact of Pesticides}

Cabbage cultivation in the Tamale Metropolis varies widely between farmers. Some use integrated control strategies whilst others depend solely on scheduled applications of pesticides. There are reports of undesirable effects of pesticides on humans that include acute and chronic health problems on wild birds, mammals, fishes, beneficial organisms and through contaminated soil and water. There are numerous pesticide active ingredients and each has a different impact on human health and the environment, and a different mechanism of pest control (Fernandez-Cornejo and Jans, 1995).

Hence, in this survey, the potential impact of the specific pesticides used by farmers on human health and the environment were approximately quantified using the Environmental Impact Quotient (EIQ) concept developed by Kovach et al. (1992). The EIQ values are based on the potential effects of the active ingredients on farm workers, consumers and the environment. The scores for the potential risk for pesticides are based on measures of toxicity (LD50) of potential exposure (such as the half-life, run off or leaching potential) and pattern of use. Toxicity and indices of exposure were assessed by scoring from 1 to 5 (as done by Kovach et al., 1992). The total potential impact could be calculated by summing EIQ values for all applications. In this study, EIQ values are shown for each individual application and are divided into three categories: low impact (0-20), medium impact (21-40) and high impact (41-60) of the pesticides on humans and the environment.

\section{RESULTS}

\subsection{Farmers' Background}

The cabbage farming system in Tamale Metropolis typically consisted of smallholder farmers growing two different varieties in areas with average farm size ranging from 0.11 to 1.50 ha (Table 1). The farms in Bilpiela and Gurugu were below average in size, while those in Choggu and Kamina were above average size. The farmers' median age was between 40 and 49 years (43\% in this class) in all sites and few farmers were more than 59 years old (5\%). The most common education level was non-formal education (43\%), followed by $37 \%$ with basic education, $15 \%$ with secondary education and $5 \%$ with tertiary education. Production sites such as Sangani, Kamina and Vitting recorded no farmer attaining tertiary education levels.

The farmers rarely had formal education in pest management, only a few of them said they received training from the Metropolitan Agriculture Development Unit (MADU); for others, their knowledge is mostly gained from experience with their parents, work on other farms or by asking other farmers. The respondents included $11 \%$ with more than 15 years of experience, the highest number with this level of experience being 2 farmers each from Bilpiela, Gumbihini and Kamina. Most farmers (49\%) had between 6 and 10 years experience. Fifteen percent $(15 \%)$ and $25 \%$ of the farmers had $11-15$ years and $1-5$ years experience, respectively. Most farmers $(67 \%)$ grew one or two different cabbage varieties. The most popular varieties grown are the English cabbage (Brassica olearacea var. capitata, $98 \%$ ) and the Chinese cabbage (Brassica pekinensis, $27 \%$ ). All farmers in all the production sites, with the exception of Gurugu, were found to cultivate both cabbage varieties in a season. 
Table 1: Comparative demography of cabbage producers in Tamale Metropolis of Ghana, 2012

\begin{tabular}{|c|c|c|c|c|c|c|c|c|}
\hline \multirow[t]{2}{*}{ Characteristics } & \multicolumn{7}{|c|}{ Number of farmers $(n=70)$} & \multirow[t]{2}{*}{ Overall (\%) } \\
\hline & & & & & & 6 & 7 & \\
\hline \multicolumn{9}{|l|}{ Farm size (ha) } \\
\hline$<0.1$ & 6 & 2 & 0 & 0 & 5 & 1 & 1 & $15(21)$ \\
\hline $0.11-0.5$ & 1 & 4 & 2 & 5 & 2 & 1 & 5 & $20(27)$ \\
\hline $0.51-1.0$ & 2 & 2 & 4 & 4 & 1 & 4 & 2 & $23(29)$ \\
\hline$>1.0$ & 1 & 2 & 4 & 1 & 2 & 4 & 2 & $16(22)$ \\
\hline \multicolumn{9}{|l|}{ Land tenure } \\
\hline State owned & 1 & 2 & 0 & 2 & 5 & 7 & 6 & $23(32)$ \\
\hline Communal owned & 6 & 5 & 7 & 6 & 2 & 2 & 3 & $31(45)$ \\
\hline Self owned & 3 & 3 & 3 & 2 & 3 & 1 & 1 & $16(23)$ \\
\hline \multicolumn{9}{|l|}{ Age (years) } \\
\hline $20-29$ & 0 & 1 & 1 & 0 & 1 & 2 & 1 & $6(8)$ \\
\hline $30-39$ & 4 & 2 & 2 & 2 & 3 & 5 & 3 & $21(31)$ \\
\hline $40-49$ & 3 & 5 & 6 & 5 & 5 & 2 & 4 & $30(43)$ \\
\hline $50-59$ & 2 & 1 & 1 & 3 & 0 & 1 & 1 & $9(13)$ \\
\hline$>59$ & 1 & 1 & 0 & 0 & 1 & 0 & 1 & $4(5)$ \\
\hline \multicolumn{9}{|l|}{ Educational background } \\
\hline Non-formal & 3 & 4 & 3 & 3 & 6 & 4 & 7 & $30(43)$ \\
\hline Basic & 4 & 4 & 5 & 5 & 2 & 4 & 2 & $26(37)$ \\
\hline Secondary & 2 & 2 & 1 & 1 & 1 & 2 & 1 & $10(15)$ \\
\hline Tertiary & 1 & 0 & 1 & 1 & 1 & 0 & 0 & $4(5)$ \\
\hline \multicolumn{9}{|l|}{ Production experience (Yrs) } \\
\hline $1-5$ & 2 & 0 & 3 & 1 & 2 & 1 & 2 & $11(15)$ \\
\hline $6-10$ & 5 & 7 & 4 & 4 & 6 & 4 & 4 & $34(49)$ \\
\hline $11-15$ & 1 & 2 & 3 & 3 & 2 & 3 & 3 & $17(25)$ \\
\hline$>15$ & 2 & 1 & 0 & 2 & 0 & 2 & 1 & $8(11)$ \\
\hline \multicolumn{9}{|l|}{ Cultivated varieties } \\
\hline English cabbage & 10 & 10 & 10 & 10 & 10 & 9 & 10 & $69(98)$ \\
\hline Chinese cabbage & 4 & 2 & 5 & 4 & 0 & 5 & 4 & $19(27)$ \\
\hline
\end{tabular}

$\mathrm{n}=$ number of farmers interviewed

${ }^{*} 1$ = Bilpiela, 2 = Sangani, 3 = Choggu, 4 = Gumbihini, 5 = Gurugu, $6=$ Kamina, 7 = Vitting

Table 2: Insecticides used by farmers to control cabbage pests in Tamale Metropolis of Ghana,

\begin{tabular}{|c|c|c|c|}
\hline \multicolumn{4}{|c|}{2012} \\
\hline $\begin{array}{l}\text { Insecticide } \\
\text { formulation }\end{array}$ & Active ingredient & $\mathrm{EIQ}$ value ${ }^{1}$ & $\begin{array}{l}\text { Number of farmers }(\%) \\
(\mathrm{n}=70)\end{array}$ \\
\hline Combicot & Chlorpyriphos & 10.0 & $40(57)$ \\
\hline Agrimec & Abamectin & 13.5 & $36(51)$ \\
\hline Dicare & Fenoxycarb & 13.5 & $11(15)$ \\
\hline Dicis & Deltamethrin & 14.0 & $14(20)$ \\
\hline Atabron & Chlorfluazuron & 17.5 & $7(10)$ \\
\hline Kombat & Lambda-cyhalothrin & 43.0 & $37(52)$ \\
\hline Zap & Lambda-cyhalothrin & 34.0 & 33 (47) \\
\hline Pawa & Lambda-cyhalothrin & 35.5 & $20(28)$ \\
\hline Pegasus & Diafenthiuron & 38.5 & $8(11)$ \\
\hline Lambda-super & Lambda-cyhalothrin & 45.5 & $50(71)$ \\
\hline Steward & Indoxacarb & 49.0 & $14(20)$ \\
\hline Karate & Lambda-cyhalothrin & 52.5 & $26(37)$ \\
\hline
\end{tabular}

\section{Knowledge of Insect Pests and their Management}

The most prominent pests of cabbage observed at the sites included the diamondback moth (DBM) (Plutella xylostella), black cutworm (Agrotis ipsilon) and armyworms (Spodoptera exampta). Other pests of minor importance included grasshoppers (Zonocerus sp and leafhoppers (Empoasca sp) (Figure 2). In general, all pest species were found to be present at virtually all growth stages of the cabbage crop. The farmers interviewed 
knew the identity and damage caused by the pests because these pests occurred frequently and were easily visible in the field. Farmers rank $P$. xylostella as the main pest throughout the growing periods with population abundance being $43 \%$ and $65 \%$ during the vegetative and heading periods, respectively. The highest abundance (12\%) of $A$. ipsilon was recognized during the seedling growth period. All the farmers indicated that their major means of controlling these pests was by the use of chemical insecticides. Other pest control methods such as biological and pheromone trapping were virtually unknown to the farmers

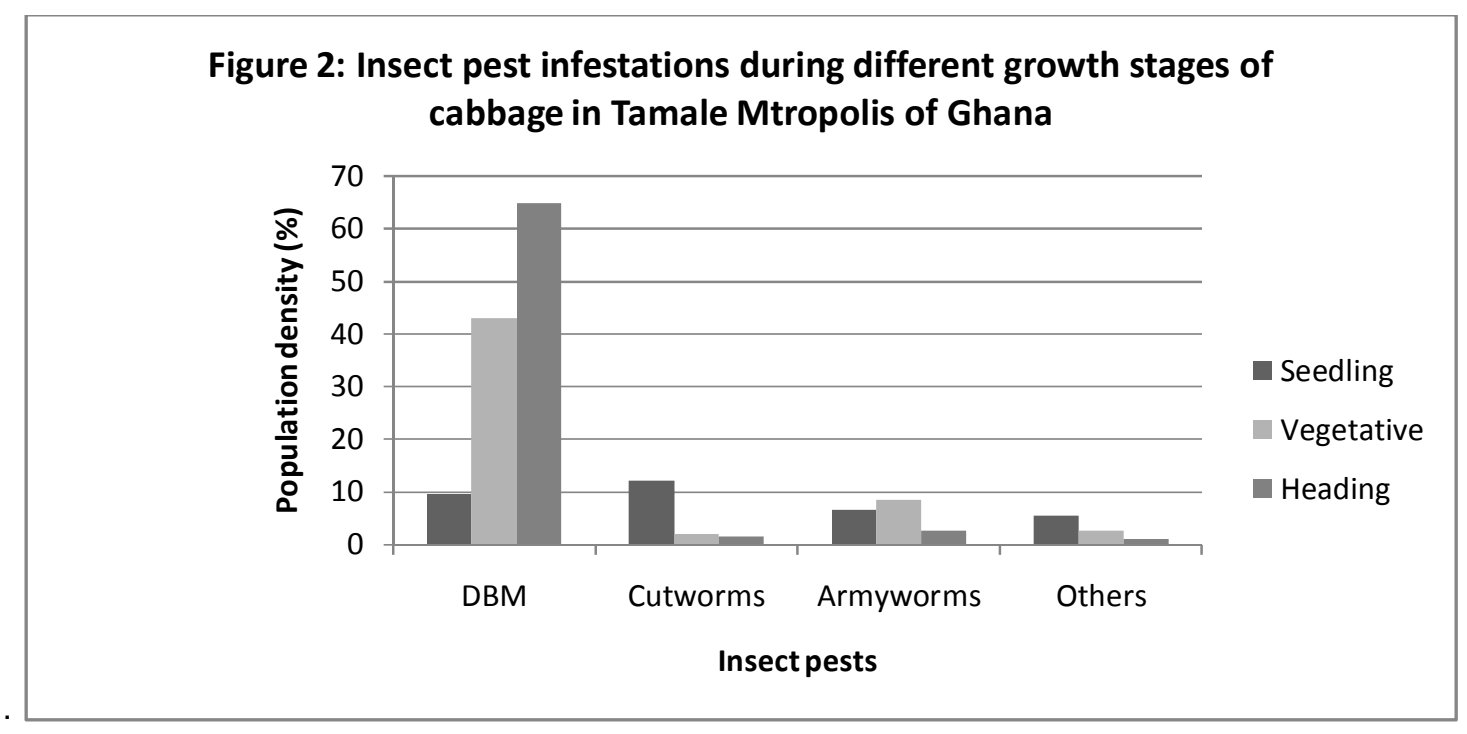

\section{Insecticides and their toxicity}

From the survey, a total of 12 different insecticides were found to be used by respondents on cabbage, however, some products have the same active ingredient (a.i) but were marketed under different trade names. Only the most commonly used a.i and trade names of insecticides are listed. The EIQ values of the insecticides ranged between 10.0 and 52.5 (Table 2). Farmers usually applied several types of insecticides during a cropping season. Majority of the farmers answered that they used 3-4 types of insecticides either within that cropping season or within the previous cropping season. Pesticides that recorded the highest rate of use included Lambda-super (70\%), Kombicot (57\%) and Kombat (52\%). These insecticides contain Lambda-cyhalothrin which can act both as systemic and contact poisons. Those insecticides that recorded the lowest rate of use were Atabom (10\%), Pegasus (11\%) and Dicare (15\%).

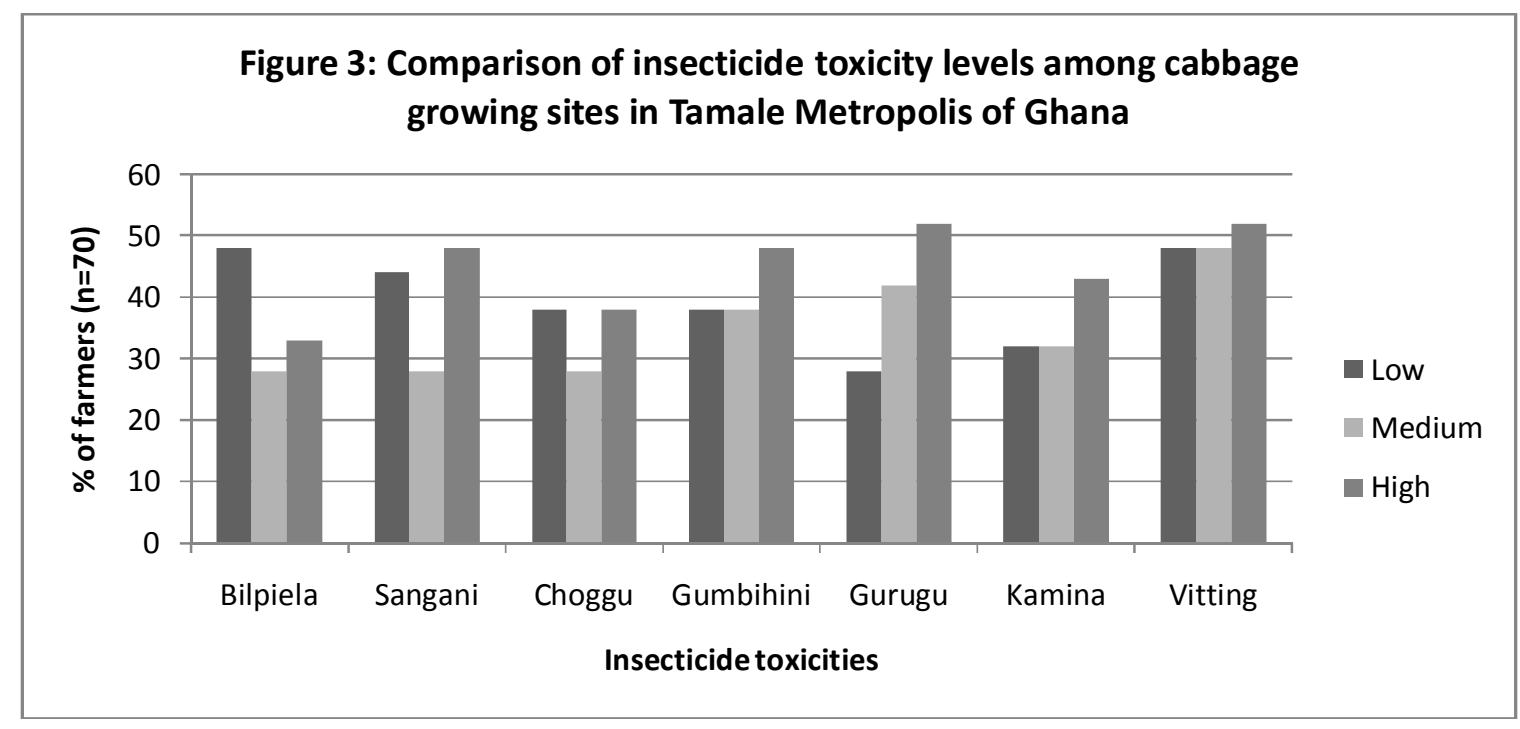


The EIQ unit is used to demonstrate the hazard of pesticide use to the environment and humans. There are significant differences in the toxicity of insecticides used across the sites, low toxicity insecticides were used by an average of $45 \%$ farmers $(P=0.012, s p=0.576)$, medium toxicity were used by an average of $40 \%$ of farmers $(p=0.594, s p=0.279)$ while high toxicity products had an average of $50 \%$ usage $(p=0.005, s p=$ 0.002), as shown in Figure 3. For individual product EIQ values, the highest usage of both low toxicity and high toxicity insecticides are from Vitting with $52 \%$ and $48 \%$, respectively. Growers are likely to have used several types of insecticide during a crop season and they may have used both low and high EIQ value insecticides in the same crop. The high toxicity insecticides were most common in all the production sites as shown in Figure 4. When the total EIQ value of all insecticides used by growers in a site was calculated, Choggu and Kamina showed the lowest mean total EIQ value, while Vitting had the highest mean total EIQ value as shown in Table 2. This may be due to differences in the levels of education, since there were a number of educated farmers in Choggu and Kamina compared to other production sites.

\subsection{Insecticide Application Patterns}

The use of chemical insecticides was the major means of pest control by farmers. Many of the growers indicated that they do spot checks for pests before spraying; the frequency of spraying still indicated a calendar spray pattern with spraying every 6-10 days in most cases $(51 \%)$. However, there is a significant difference $(p=$ 0.0001 ) in spraying frequency between the wet and dry seasons. During the wet season, farmers sprayed more frequently, with 6-10 days between each spraying. The highest percentages of 6-10 day interval spraying during the wet season are in Bilpiela (13\%) and Gumbihini (11\%) (Figure 3). Farmers stated that the most common reason for the increased use of pesticides during the wet season was that the pesticide was washed off more quickly; hence pest infestation was more severe during the rainy season.

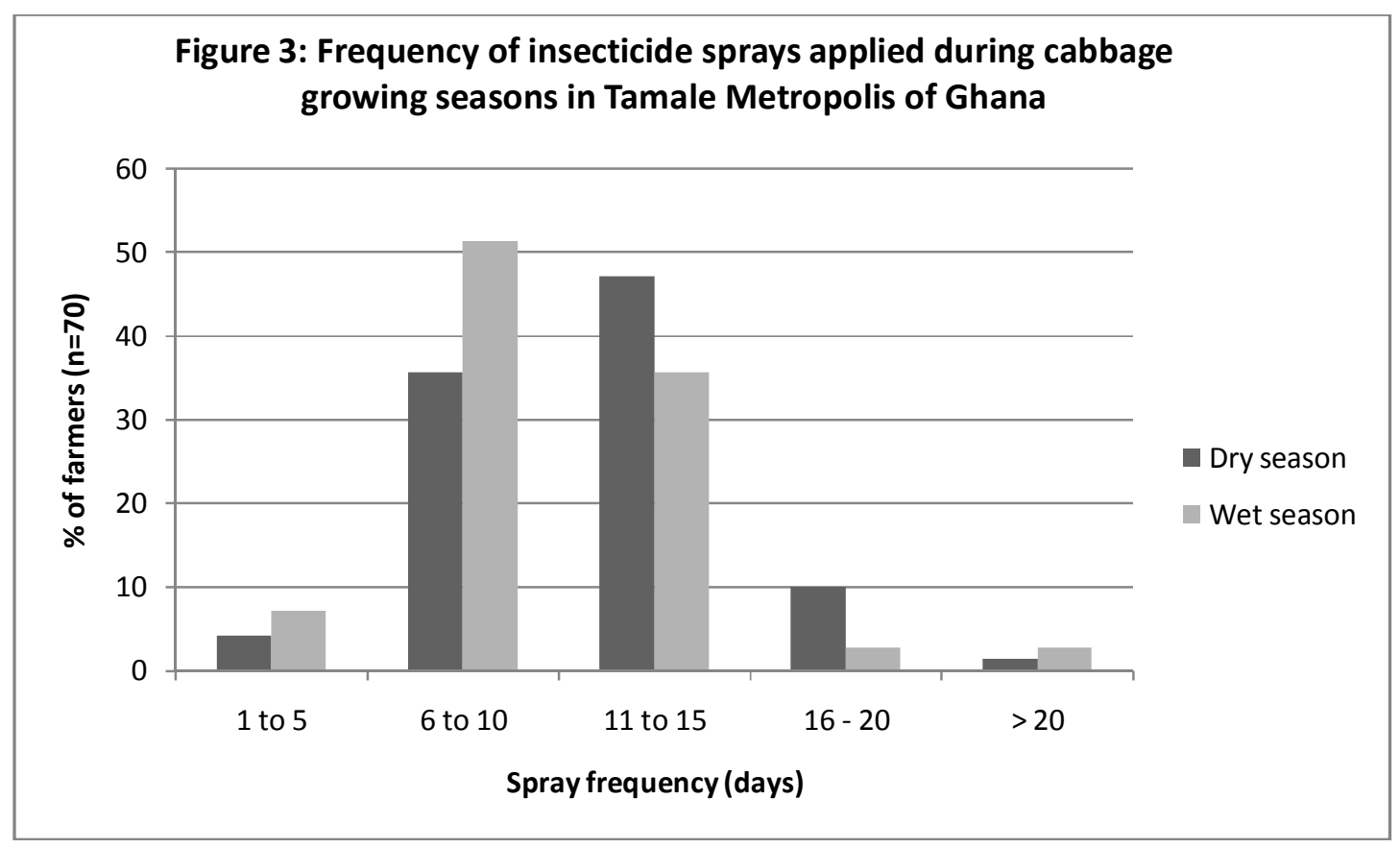

\section{Production Cost and Market Chain}

The production cost of the cabbage included land preparation and planting, fertilization, irrigation, pest control and harvesting. The growers were reluctant or unable to give detailed information on each individual factor cost. Therefore, the cost was estimated only as the total cost of production on their farms. The reported production costs varied from US $\$ 400$ to $700 / \mathrm{Ha}$, with the average cost US $\$ 550 / \mathrm{Ha}$. Production costs reduced with increased total farm size (Figure 5), probably due to high fixed cost factors such as tractor or bullock use, giving greater efficiency on larger farms. 


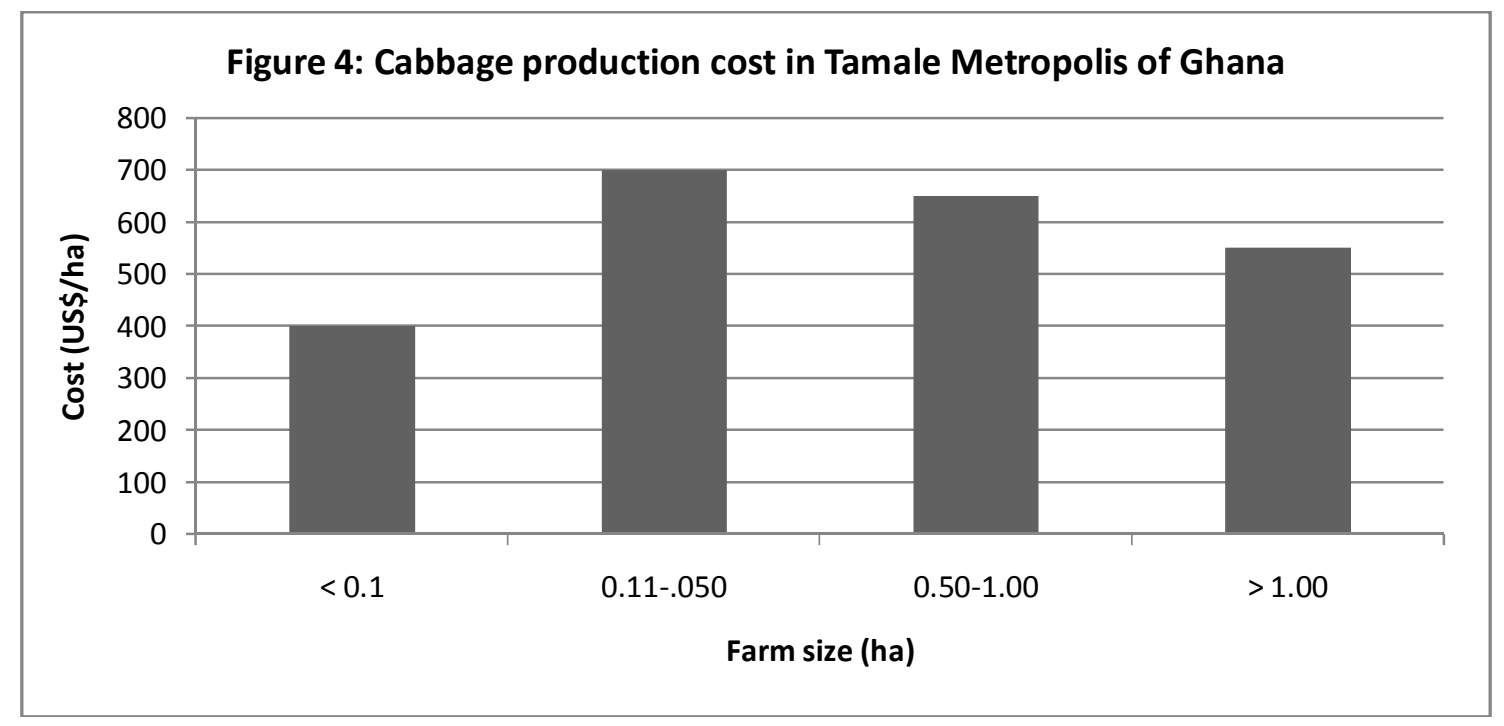

Growers were asked where or to whom they usually sell their produce. Few farmers who responded usually provided more than one answer to this question, while majority of them were reluctant or unable to disclose their produce marketing channels. The study shows that some of growers sent their produce to a wholesaler; others had a contract, while others went to local markets. Small truck operators collect the produce from farms, and then send it to collection centres, usually located beside a main road or in towns. Growers who sell their produce to wholesalers usually sell on a consignment basis via transport operators. The price of transport is usually divided between the farmer and wholesaler. Normally, the operators sell the produce to two major wholesale markets, at Aboabo and Central markets, both within the Tamale Metropolis. The wholesale markets are suppliers for a wide range of retailers, including hypermarkets, super markets, groceries, restaurants and hotels.

\section{DISCUSSION}

The results from this study show that most cultivating cabbage since they were young and rarely with formal training. Generally their experience was gained through working with their parents and friends, thus the cultivation and pest control methods are almost the same as found by Mazlan and Mumford (2004) who reported that the young gain their experience through working with their parents and friends. About $7 \%$ of growers can be considered newcomers (with experience of 1-5 years), some being workers in other vegetable farms or young farmers who start independently from their parents. Despite high costs of farm management, there were still opportunities in vegetable production in the Metropolis. The results revealed that small sizes of land were put under cabbage cultivation. This confirms the findings of Horna et al., (2008) who reported that small sizes of plot less than 0.5 ha on the average were put under cultivation of cabbage and this could be attributed to encroachment by farmers on the land during the dry season for other farming activities.

In pest control, farmers rely on pesticides, with quantities applied often being independent of infestation levels. The use of IPM methods was low, with only $16 \%$ of the respondents following these methods. However, the results show an increased use of IPM compared to the survey conducted by Midmore et al. (1996), who found less than $10 \%$ of farmers following an IPM programme in the Cameron Highlands. Many growers have actually adopted IPM strategies without being part of any IPM programme. Some perform larvae counts, use crop rotation and pheromone traps and know the incidence of parasitoids. However, the practices they follow are not thorough. Even though they followed a crop rotation, the types of crop they used were often from the same families which are also hosts for P. xylostella. Many of them either apply more pesticides or switch to new pesticides when $P$. xylostella develops resistance to the older types of pesticide. Nevertheless, this practice could not sustain the effectiveness of the latest products as $\mathrm{P}$. xylostella will build up resistance to these technologies, as happened on Bt and other synthetic pesticides (Sayyed and Wright, 2001). Timbila (1993) reported that $P$. xylostella had become resistant to almost all available synthetic insecticides in Ghana.

The increased pressure to maintain high levels of cabbage production with high physical quality for both domestic consumption and export has resulted in increased use of pesticides on fresh produce. The continued high use of pesticides is a problem for farmers' health and the environment (Waibel and Schmidt, 2000). In order to minimize further damage, alternative or redesigned methods of pest control and stricter food safety regulations must be implemented. To reduce the use of pesticides and thus improve food quality, there is a need to look at 
the flow of pesticide residues through the fresh produce supply chain. Currently, this task is the responsibility of the Plant Protection and Regulatory Services Directorate (PPRSD) under the Ministry of Food and Agriculture MoFA) and the Food Quality Control Division (FQCD) under the Ministry of Health $(\mathrm{MoH})$. The upstream responsibility resides solely with PPRSD, which conducts regular pesticide residue monitoring on a sample of farms, while downstream in the chain, pesticide residues are monitored by FQCD by collecting samples at the farm gate. At this point, if the samples were found to breach the Maximum Residue Level (MRL), the grower can be charged with a penalty fine, and/or the produce intercepted and destroyed. To achieve the objective of safer food through reduced use of pesticides, produce must be able to be traced at any point in the supply chain. This could only be achieved by labeling of the produce from source through to sale. When a traceability programme is established, the responsibilities of pesticide residue monitoring should include wholesalers and retailers and not just the PPRSD and FQCD.

The monitoring could then be performed at a later stage in the food chain. This would be more efficient in comparison with the current practice. As produce goes through the food chain, cleaning occurs which reduces residues (Soliman, 2001), thus when pesticide residues are monitored at later stages, the residues may be lower than in farm gate samples, avoiding unnecessary rejections. Also, for fairness, the grower should not be the only party penalized when produce is detected with pesticide residues over the MRLs. The retailer could also be made partially responsible by using the 'name and shame' method. Consumers depend on retailers to provide them with safe produce, and retailers could fulfill their responsibility through stricter contracts with suppliers or greater selectivity in choosing suppliers (Hu et al., 2004).

The role of retailers such as supermarkets and hypermarkets supplying fresh produce in Ghana is increasing, as in other parts of the world (Hu et al., 2004). This is due to changing demand from consumers with higher incomes and health awareness. This retail trend is especially seen in highly urbanised areas; Accra and Kumasi with the number of hypermarkets and supermarkets increasing over the years. This shows that supermarkets could play an important role by imposing on their standards and grades of fresh produce by buying on contract directly from known growers. At present, the demand for local pesticide-free produce is beginning to increase in African and Asian cities (Midmore and Jansen, 2003), including those in Ghana. Communities with higher incomes and education are more concerned about the effects of pesticide residues, thus they are willing to pay a higher price for safer food. With the increased role of supermarkets and hypermarkets in the food supply chain, a traceability programme could be enforced throughout the supply chain cycle. Pesticide residues could be monitored not only at the farm gate, but also at the selling point, and supermarkets would take greater responsibility. The grower would be forced indirectly to grow safer produce for their markets. Eventually, the objectives of reducing the use of pesticides and improving food quality can be achieved if there is involvement of all stakeholders in the food value chain and transparency of residue test results.

\section{Acknowledgements}

The administration of the Department of Agronomy of the University for Development Studies, Tamale, Ghana, provided the logistics for the survey study.

\section{References}

Fernandez-Cornejo J, Jans S (1995). Quality-adjusted price and quantity indices for pesticides. Am. J.Agric. Econ. 77, 645-659.

Horna D, Melinda S, Ramatu A, Fallck-Zepeda J,Timpo SE (2008). Insecticide use in vegetables in Ghana: would GM seed benefit farmers? Paper presented at the American Economic Association Annual Meeting, Orlando, USA, July 27-29, 2008.

Hu D, Reardon T, Rozelle S, Timmer P, Wang H (2004). The emergence of supermarkets with Chinese characteristics:challenges and opportunities for China's agricultural development. Dev. Policy Rev. 2:34-40.

lqbal M,Verkerk RHJ, Furlong MJ, Ong PC, Syed AR, Wright DJ (1996). Evidence for resistance to Bacillus thuringiensis (Bt) subsp. kurstaki HD-1, Bt subsp, Aizawai and Abamectin in field populations of Plutella xylostella from Malaysia. Pestic. Sci. 48, 89-97.

Kovach J, Petzoldt J, Degni J, Tette J (1992). A method to measure the environmental impact of pesticides. NY Food Life Sci. Bull. 139, 1-8.

Midmore DJ, Jansen HGP (2003). Supplying vegetables to African and Asian cities: is there a case for peri-urban production? Food Policy 28, 13-27.

Midmore DJ, Jansen HGP, Dumsday RG (1996). Soil erosion and environmental impact of vegetable production in the Cameron Highlands, Malaysia. Agri. Ecosyst. Environ. 60, 29-46.

Ooi, P.A.C. (1986). Diamondback moth in Malaysia. In: Talekar,N.S., Griggs,T.D. (Eds.), Diamondback Moth Management: Proceedings of the First International Workshop, AVRDC. Shanhua, Taiwan, pp. 25-34. 
Ooi, P.A.C., Lim, G.S. (1983). Introduction of exotic parasitoids to control the diamondback moth in Malaysia. J. Plant Prot. Tropics 6,103-111.SARI (2008). Savanna Agricultural Research Institute. Annual Report 2008, 153pp.

Sayyed, A. H., Wright, D.J. (2001). Cross-resistance and inheritance of resistance to Bacillus thuriengiensis toxin Cry 1 AC in diamondback moth (Plutella xylostella L) from lowland Malaysia. Pest Manage. Sci. 57, 413421.

Soliman, K. M. (2001). Changes in concentration of pesticide residues in potatoes during washing and home preparation. Food Chem. Toxicol. 39,887-891.

Syed, A.R. (1992). Insecticide resistance in diamondback moth in Malaysia. In: Talekar,N.S. (Ed.), Management of DBM and other Cruciferous Pests. Diamondback moth and Other Crucifer Pests: Proceedings of the Second International Workshop, Tainan, Taiwan, AVRDC. Shanhua, Taiwan, pp. 437-442.

Tabashnik, B. E. (1994). Evolution of resistance to Bacillus thuriengiensis. Annu. Rev. Entomol. 39,47-79.

Timbila, J. A. (1993). Laboratory evaluation of bio pesticides against the diamondback moth, Plutella xylostella. Biocontrol Division, Crop Research Institute Kumasi Ghana. 2pp

Waibel, H., Schmidt, E. (2000). Feeding Asian cities: food production and processing issues. Paper presented at the AFMA/FAO Regional Seminar 'Feeding Asian Cities', 26-30 November, Bangkok. http://www.fao.org/fcit/mark.asp (accessed on 27/5/04).

Weaver, C.M.H. (1990). Calcium absorption from kale. American Journal of nature 51: $656-657$.

Werner J. (1993). Participatory development of agricultural innovations: Procedure and methods of on-farm research. Eschborn: Deutshe Gesellschaft fur Technische Zusammenarbeit, 251pp. 